\section{THE ANTITOXIN TREATMENT OF DIPHTHERIA.}

\section{THE PREPAR ITION OF BEHRING'S DIPHTHERIA ANTITOXIN.}

By E. KLFIN, M.D., F.R.S.

Wiтн the view of enabling those who are engaged in preparing from the horse Behring's antitoxin to obtain it in a much shorter time than the present methods permit, I take this opportunity of publishing the following notes :

I have been carrying out for the Medical Department of the Local Government Board a series of experiments that have for their object the study of the preparation and of the nature of Behring's antitoxin. The rationale of the method used by. Roux ${ }^{1}$ for obtaining from the horse Behring's antitoxin seems to me difficult of acceptance from a theoretical point. This does not, of course, imply that the serum which Roux obtains has not the antitoxic power which he claims for it; the numerous experiments described by him $^{2}$ as made on the guinea-pig, and particularly his striking curative results on the human subject, can leave no doubt as to this. What seems to me the chief difficulty of his method is that horses require in his process a very long and tedious series of numerous injections-some direct into the vessels-with enormous quantities of pure diphtheria toxin (sometimes $200 \mathrm{cccm}$. of pure toxin in a single injection) for the production by them of serum of considerable antitoxic power. Roux explains his procedure by assuming that by injection of increasing quantities of pure strong toxin, the tissues of the horse are again and again stimulated and sustained in their formation (secretion) of antitoxin.

In all infectious diseases the degree of resistance to a given disease acquired by one or more previous infections rests with the blood and the tissues. In some of the infectious diseases-for example, small-pox, scarlet fever, anthrax - this condition of resistance against a fresh infection amounts to almost complete immunity. This condition of resistance is brought about by, and (as far as we know at present) depends on, the growth and life processes of the specific microbe in the infected body during the antecedent attacks, whether natural or experimental. The precise manner, however, in which this condition of resistance is created is as yet not clearly made out. Various views have been put forward to explain it, which it is not necessary to enter into here ; they are all (including Roux's) based more or less on assumptions. The chief facts experimentally established by the researches of Behring, Kitasato, R. Pfeiffer, Wassermann, and others are that the blood of an animal which has acquired immunity possesses antitoxic property, and that the degree of antitoxic property of the blood stands in direct relation to the degree of resistance acquired by the animal furnishing it. Further, this antitoxic property of the blood not only renders the particular animal, but also other animals into which it is introduced capable of overcoming and of withstanding the disease that is in question. In the case of the sheep and goat Behring has shown that it is possible by repeated diphtheria injections to render these animals gradually highly tolerant against diphtheria, and at the same time to confer on their blood a high degree of antitoxic power. By virtue of this antitoxic condition of their blood small amounts of the blood serum are capable of protecting guinea-pigs against inoculation of diphtheria bacillus and of neutralising in these animals the diphtheria toxin if it be injected. The two substances-toxin and antitoxin-are, then, in their proper proportions, mutually antagonistic.

Now Roux, as I have said, introduces over and over again large amounts of pure diphtheria toxin into a horse which has already by previous injections of the pure toxin been rendered to a certain extent resistant against this toxin (it is because of this resistance that he finds it necessary to increase the dose of the toxin), that is to say, a horse that has by previous injections of diphtheria toxin become more or less resistant must possess a corresponding amount of antitoxin in its blood. But since the two substances, namely, toxin and antitoxin, are antagonistic and neutralise one another, it follows that each successive injection of a large quantity of pure diphtheria toxin into a given horse must neutralise a proportionate amount of antitoxin already formed and present in the blood of the animal. This possibly explains the extraordinarily long time which Roux's horses take before their blood is rendered sufficiently antitoxic. These considerations led me to adopt a different plan in the preparation of antitoxin serum from the horse-a plan, indeed, which corresponds more closely than Roux's to the natural process. By this plan I have succeeded in obtaining from the horse antitoxic serum in a far shorter time than is possible by Roux's plan; and, as observation proves, this serum is possessed of considerable antitoxic power. The principle of my method is as follows: By a few injections of attenuated living bacilli - the attenuation is due to age of the culture-along with their toxin into the horse, this animal is furnished with a certain degree of resistance. Next, large quantities of living diphtheria bacilli (minus their toxin) taken from the surface of solid cultures of gradually increasing virulence are repeatedly injected subcutaneously, so as to allow the bacilli to grow and to multiply, and to gradually produce within the body of the animal, as is the case in the natural order of things, the toxin and ultimately the antitoxin.

Every such injection on my plan is followed by a temporary reaction; a rise of temperature varying between $0.5^{\circ}$ and $1.8^{\circ} \mathrm{C}$., and a local tumour; but there is no suppuration at the seat of inoculation. As soon as one such tumour has disappeared, a new injection is made, as stated above, with large quantities of living bacilli scraped from the surface of solid media (agar and gelatine). By the third week the animal will bear the scrapings from the surface of two whole agar cultures of virulent character. In the case of one horse $I$, by this method, obtained antitoxin serum in twenty-three days, in another horse in twenty-six days, from the date of the first injection. If, after the first bleeding of the horse, it be again twice or thrice injected with virulent living bacilli (taken from the surface cultures), the further serum obtained from such horse posesses even increased antitoxic power.

The antitoxic power of the serum in the twenty-three and twenty-six days horse was tested on guinea-pigs, and it was found that one part of serum was capable of protecting 20,000 to 40,000 grammes body weight of guinea-pig against the living bacilli and toxin (not merely against pure toxin); considerably more than a fatal dose of living bacilli having been injected. This serum has been used in cases of diphtheria on the human subject, some of them very severe cases. It was injected in doses of $5 \mathrm{c.cm}$ to 8 or $10 \mathrm{c.cm}$., and in severe cases the injection was repeated within twenty-four hours. The result was highly satisfactory. In some severe cases it was particularly striking ; further spread of membrane being entirely arrested, and rapid loosening and discharge of the existing membrane being also a conspicuous feature.

\section{THE NATURE OF DIPHTHERIA AND THE BASIS OF} THE ANTITOXIC TREATMENT.

AT the request of the British Institute of Public Health, Dr. G. Sims Woodhead gave a lecture on the antitoxic serum treatment of diphtheria at the Examination Hall, Victoria Embankment, on December 7 th. He observed that important points to bear in mind were that the organism producing the disease was a perfectly well defined one; that while the lymph which formed the membrane lay partly among the epithelial cells the bacteria were chiefly found on and near the free surface, thus practically outside the body; that the bacteria did not enter the tissues, but produced toxic substances probably of the nature of enzymes; that these were absorbed, and, acting on the blood and tissues, produced substances which have been shown by Sidney Martin to be of at least two kinds-acid and toxalbumins; that these among other poisonous properties had the power of causing fatty degeneration of the muscles and inflammation and degenera- 
tion of nervous structures; and that the symptoms and dangers of the disease and of its sequelæ arose largely from the effect on the economy of these poisonous products.

The method of bacteriological diagnosis, which is now about to be undertaken at the Laboratories for the Metropolitan Asylums Board, was then described, and it was pointed out that, although in doubtful cases it might be necessary to employ secondary cultures, in the great majority of cases the fact that the diphtheria bacillus grew in the culture media far more rapidly than did any other organism commonly found in the mouth or pharynx, made it possible very often to speak with great certainty as to their presence in about twenty hours.

Dr. Woodhead next described the steps and the lines of thought by which investigators had been led up to the current conception of the antagonistic nature of toxins and antitoxins. We must assume, he said, that the disease produces toxic substances, which in proportion to their quantity injure the tissues; that in time and by degrees the tissues become indifferent to them, in other words, immune; that in the meantime protection is obtained by the production in the blc od and tissues of protective substances which when mixed with the toxins neutralised them, or at any rate their effects, and are therefore spoken of as antitoxins; that this antagonism between toxins and antitoxins can be shown to take place even outside the body in test tubes, so that known lethal doses of toxins can be rendered inert and harmless by admixture with the antitoxic serum of animals recently rendered immune; that when patients die from diphtheria it is probably because they cannot form sufficient antitoxin in a sufficiently short time; that the injection of antitoxin-containing serum can render certain rodents quite immune to the disease and can cure it after it is set up; and that the endeavour in the same way to cure the disease in the human subject by injecting the serum of animals, which have been made to produce large quantities of antitoxins by repeated injection of toxins, has likewise been attended with results of a most satisfactory character.

The process of producing in quantity the toxins required to rouse the antitoxin-producing power to full activity in the animals employed was then described, and emphasis was laid on the fact that the horses used were not made ill by the proceedings, and that the pain was of the slightest character.

Dr. Woodhead insisted on the fact that diphtheria was essentially due to a manufacture of poison taking place practically outside the body, and that if, while attacking the disease at its source, we can at the same time neutralise the poisons that are being diffused into the body, we have complete control over the disease, and that when it is once got under we need have little or no fear of its return. The necessity of early treatment depended not on any inability on the part of the antitoxins to neutralise the toxins then existing, but on the fact that they could not undo damage already done to muscle or nerve, and could not inhibit those secondary septic processes with which diphtheria sometimes soon became complicated. In regard to the questions which had been raised as to the possibility of glanders or tuberculosis being transmitted, the obvious answer was that serum was never taken from animals so diseased. By aid of mallein and tuberculin the animal could very readily be proved to be in good health so far as those two diseases were concerned.

In proposing a vote of thanks Lord Playfarr said that with the evidence before them it would be a scandal and a crime if owing to the feelings of certain persons, whose motives he honoured, with regard to inflicting pain on animals, they failed to give the children of England the benefit of the treatment.

Dr. Thorne Thorne, C.B., Medical Officer to the Local Government Board, in seconding the proposition, said he could not but feel that we had arrived at a crisis in our knowledge of the natural history of the infectious diseases of man. That there existed some link between certain of the specific contagia in man and those of the lower animals they had known for many years. There loomed behind these scientific researches a question he had often put to himself-Was it possible that man had not always been heir to those specific contagia by which in historic times the human race had so often been devasted? Was it not rather that by reason of unnatural methods of life he had acquired specific infections which in the lower animals were well nigh if not altogether benign but which by transference to man had acquired a potency before unknown? And if so, might we not now be learning that if we would reduce these specific contagia to their original level of trivial potency and in the end secure their annihilation, we must take them back to the lower animals with all their altered virulence and find in the bodies of these animals the medium by which they might be reduced to comparative or complete impotency? The question might be bold, but he hoped it might not be deemed over-bold.

THE ANTI.SCIENCE PROTEST.

At the fortnightly meeting of the Metropolitan Asylums Board held on Saturday, December 8th, a deputation, headed with filial feeling by Lord Coleridge, presented a memorial against experiments being carried out in the Board's hospitals on the use of the antitoxin treatment of diphtheria.

The question was brought up by the report of the General Purposes Committee, presented by Mr. Augustus Scovell, which recommended the Board to accept the offer made by the Royal Colleges of Physicians and Surgeons, in response to their inquiries, to supply antitoxin to the medical superintendents of the managers' hospitals, provided they were supplied with the necessary horses, stabling, grooming, keep, etc., together with railway fares and incidental laboratory expenses. The accommodation required would be for not less than four nor more than ten horses.

Lord Coleridge raised objections, on the ground that public funds ought not to be devoted to what he chose to call experiments in physiology; that it ought to be proved that the treatment was a cure and would do no harm; that many of the patients under the control of the Board were compulsorily so, and many were children, and that none were in a position to decide on the very difficult question of medical treatment.

Notwithstanding his remarks, however, the Board by a large majority accepted the report of the Committee.

\section{BACTERIOLOGICAL EXAMINATION FOR THE} LOCAL GOVERNMENT BOARD.

THE step which the medical department of the Local Government Board are taking with a view of facilitating the early diagnosis of diphtheria on the part of local medical officers of health deserves commendation; and it should be noted that the fact that the material from one typical attack, if it prove not to be diphtheria, would not seem to preclude the transmission of further material if occasion demand it from the same neighbourhood, although it is distinctly stated that when once Dr. Klein has satisfied himself that the disease is diphtheria, no more material from cases of the same prevalence will be examined. Thus it appears open to a health officer, who has reason to fear the development of graver symptoms in reported attacks from throat maladies, to ease his mind by submission of additional material to headquarters. At least this is how we read the memorandum of conditions, and we trust we read them aright, since it will avail little for a health officer to receive a negative report on a solitary attack of obscure sickness which may be followed by others of more pronounced type.

Dr. I. BuRner Yво (Professor of Clinical Therapeutics at King's College, London) writes: In order to compare profitably the different observations of practitioners who have used antitoxin serum in the treatment of diphtheria it is obviously most important that they should employ as nearly as possible uniform doses of a uniform preparation. The concentrated serums produced by manufacturing chemists in Germany are far more likely to err in want of uniformity of strength and in uncertainty of action than the pure serum as used by Roux of the Pasteur Institute; and it is also probable that even the pure serum obtained from different horses will vary somewhat in activity. It is clear, however, there can be no useful comparison of such results as are recorded in the British Medical Journal of December 8th. In one (Dr. Hamilton's) we are told the " antitoxin produced no marked improvement;" and we look to the dose and we 
find the child received at first 15 minims and, six hours afterwards, 5 minims, the case being a severe one. In the case reported by Dr. Mules, who has been "disappointed" with antitoxin serum, and who had two fatal cases in which it was injected-obviously, therefore, very severe cases-we find, in the first case, one dose only of 20 minims was given, and in the second case two doses of 15 minims, with an interval of twenty-four hours, were given, and these are termed "full" doses. In Mr. Ross Sutton's case we notice that a child of the same age as the preceding received two doses also. with an interval of about twelve hours, but of exactly double the quantity, the same serum (Aronson's) having been used in both cases; so that this case received in twelve hours exactly four times the amount of antitoxin serum received by the previous one, and Mr. Sutton does not appear to have been "disappointed."

In Mr. Steele's case, an adult, the first dose was $20 \mathrm{c.cm}$. of antitoxin serum, obtained from Dr. Ruffer (the c.cm. measures in use in this country, I find, differ slightly, giving about 15 to 17 minims to the c.cm.), equal to over 5 drachms, and $10 \mathrm{c.cm}$. more were given the next morning, making nearly an ounce of serum altogether; and Mr. Steele also does not appear to have been "disappointed."

Roux states that his practice has been to give $20 \mathrm{c.cm}$. (over 5 drachms) of serum to each little patient on admission, and the same quantity, or half the same quantity, according to the severity of the case, twenty-four hours afterwards ; and if the pulse and temperature stilli remain high, the same dose is again given. He adds that the smallest quantity he has used has been over 5 drachms, and the largest quantity about 4 ounces; but in one exceptional case he gave as much as between 6 or 7 ounces! Practitioners should remember these facts, and that Roux's series of cases is by far the largest and most important hitherto published.

In the same issue you have published an abstract of a hostile criticism of this method by Dr. Hansemann, of Berlin, which has already been made use of by the antivivisectors in the public press in the denunciation of the antitoxin treatment. It would be unfair to criticise this criticism in what may be but an imperfect abstract, but it would not be difficult to show how disingenuous and fallacious the reasoning is as it appears therein. This will doubtless be done in the discussion which will follow this paper, and which has been postponed. I may, however, take this opportunity of expressing the hope that so undesirable and ambiguous a term as "Bretonneau's" diphtheria will not be adopted in this country.

Dr. John Patterson, M.B., etc. (Ranelton, co. Donegal, Ireland), writes : In the BRITISH Medical JounNal of December 8th you publish notes of 4 cases of diphtheria treated by Dr. P. H. Mules (Bowdon, Manchester). Two of these cases were treated on the old lines, and 2 with antitoxin; both the latter died. As antitoxin is now on its trial both by the profession and by the public at large, might I suggest that the failure of the antitoxin in these two cases may have been due to the insufficiency of the dose used20 minims for a child aged 7 , and 15 minims for a child aged 4. I am not sure of the strength of Aronson's fluid, but I have seen the dose mentioned as from 60 minims to 160 minims. Some ten days ago, through the kindness of Dr. Armand Ruffer, I had an opportunity of trying the serum (as supplied by the British Institute of Preventive Medicine) in a case of a child aged 10 . The dose I used was $10 \mathrm{c.cm}$. (roughly 160 minims). In twelve hours there was a most marked improvement in all the symptoms, both local and general. At the end of twenty-four hours $I$ injected a further dose of $5 \mathrm{c} . \mathrm{cm}$., merely as a precautionary measure.

Mr. Lennox Browne (Surgeon to the Central London Throat. Nose, and Ear Hospital) writes: I venture, with all respect to my professional brethren, to protest against the character of some of the literature which is being so lavishly supplied to the British Medical JodRnal with regard to the treatment by antitoxin of so.called diphtheria. I say "so-called" because a large proportion of the cases, including some from metropolitan hospitals, have not been verified as diphtheria by bacteriological examination, and $\mathrm{my}$ per- sonal experience confirms that of Continental and American observers, that something like two-fifths of the cases certified will not bear this test.

Taking No. XXVIII of the series published in your issue of December 8th of cases treated by antitoxin, the report supplies no evidence that the child who was admitted for scarlet fever came from a house in which there was diphtheria, nor any evidence that the child had diphtheria at all ; for, independently of the absence of a bacteriological report, there are certain points in the clinical history which require clearing up.

1. As to adenitis, was it cervical or was it submaxillary? If the former, it is characteristic of diphtheria; if the latter, of scarlet fever; while when diphtheria is planted on scarlet fever, both sets of glands are involved.

2 . Was not the rise in temperature probably as much due to the adenitis as to the laryngeal disturbance?

3 . The fact that antitoxin produced no marked improvement should further negative the diagnosis of diphtheria. And, lastly, no mention is made of paralytic sequelæ- - the only irreproachable clinical test of exact diagnosis.

No. XXXI is another example in which, neither by bacteriological examination nor by any history of paralysis, is the diagnosis confirmed. Granted that only fifteen days having elapsed between the admission of the patient and the date of the report, sufficient time has not yet been given to settle this last point, is it not a pity to make these reports so early?

I would conclude by a brief allusion to the views of Dr. Haddon. I should be prepared to contest almost every one of his points, but will content myself with quoting but one or two as especially calling for protest.

1. His remark that: "The amount of membrane, which is by no means an early sign, is of no value in prognosis, and so long as it does not extend into the larynx, its amount need cause no additional anxiety."

2 . The writer leaves the question of nasal diphtheria com. pletely out of his category of conditions to be noted before employing antitoxin. To those who may think this a rare complication, I may state that, according to original and as yet unpublished statistics which are in my possession, of 1,000 consecutive cases of the disease, the proportion of nasal diphtheria is 21.6 per cent., and of these over 64 per cent. ended fatally.

Lastly, Dr. Haddon is of opinion that "the paralytic sequelæ, so far as he has seen them, are worse in those cases in which the larynx is not affected." The same statistics show that while some form of paralysis supervened in $\mathbf{1 1 . 9}$ per cent. of the whole 1,000 cases, laryngeal diphtheria was present in 16 per cent., and these laryngeal cases were followed by paralysis in 14.3 per cent. In other words, paralysis occurred in about 10 per cent. of the cases in which the larynx was not affected, but in over 14 per cent. of those in which it was. And why should we expect it to be otherwise?

XXXII.-We are indebted to Mr. T. H. Jones, M.B. Assistant House-Surgeon, Infirmary for Children, Liverpool, for the following notes of a series of cases of diphtheria which occurred recently in that infirmary. Diphtheria antitoxin serum, furnished by $M$. Roux, of the Pasteur Institute, Paris, was used in eight out of these ten cases.

Cases under the care of Dr. P. Davidson.

CASE I.-J. T., aged 4, was admitted on August 27th, 1894. The breathing was stridulous, and there was marked recession of the chest wall and epigastrium, and cyanosis. There was membrane on the fauces, uvula, and tonsils. Tracheotomy was performed at once, and the membrane removed as far as possible. On August 29 th the membrane was not spreading, but was not separating. The urine contained one-half albumen Antitoxin $m \times x$ was injected. On August 30 th the child had a bad attack of dyspnca during the day. Antitoxin $m \mathbf{x v}$ was injected. A large piece of membrane separated from the fauces later in the day. On August 31st antitoxin $m \times v$ was injected. The tube was removed on September 1st. During the following six days the general condition improved, several pieces of membrane separat 2 , and the breathing was good. Paralysis of soft palate was noticed on September 2nd. On September 7 th the child 
became suddenly cyanosed, the pulse was very feeble, and the child died of cardiac failure.

CaSE II.-J. F., aged 8, was admitted on August 6th, suffering from acute nephritis and post-nasal adenoids. The ade. noids were scraped on August 8th. The albumen was onehalf on admission, and blood was present in the urine. By August 18th there was only a trace of albumen, and no blood. On September 28 th it was found that the fauces and uvula were much congested, and that there was membrane on each tonsil. The urine was smoky and contained a trace of albumen. The temperature was $102.8^{\circ}$. As much membrane as possible was picked off. Antitoxin $\mathrm{m} x \mathbf{x}$ was injected. For the next five days the membrane spread a little ; small pieces became detached occasionally. The temperature came down to normal on the day after the injection and remained so, with the exception of one rise to $101^{\circ}$ on the fifth day, when the membrane was found to have spread somewhat on the back wall of the pharynx. After this the membrane did not spread, but separated well, and the patches diminished in size. On October 9th no membrane remained, and it did not reappear. There was no albuminuria.

CASE III.-A nurse on October 14th presented much congestion of the throat, and membrane on each tonsil. The temperature was $103.4^{\circ}$. On October 15 th the membrane had spread. There was no albumen in the urine. Antitoxin m xxx was injected. The membrane was picked off for three days in succession. The temperature remained normal after October 15th. On October 24 th no membrane was visible, and it did not re-form. The general condition was excellent.

CASE IV.-E. N., aged 2, was admitted on September 2nd for empyema, which was incised and drained. On October 18 th the child was found to have patches of membrane on the uvula and left tonsil. The temperature was subnormal. On October 19th antitoxin $m \times x$ was injected. For five days after this the temperature varied between $99^{\circ}$ and $101^{\circ} \mathrm{F}$.; it then came down to normal, and remained so. There was never albuminuria. The general condition was bad; the chest symptoms having become aggravated at the time the diphtheria was discovered. On October 29th no membrane remained, and it did not reappear. The general condition was improved. The child remains in the hospital on account of the empyema and a post-diphtherial paralysis of the palate.

CASE V.-A nurse presented congestion of the throat, and membrane on each tonsil. On October 21 st the temperature was $101.8^{\circ}$. Local and general treatment was applied. The temperature was normal for two days after October 21st; it then rose to $102.5^{\circ}$. After that it gradually fell to normal, and remained so. There was never albuminuria. On November 2nd no membrane remained, and it did not re-form.

In Cases $I$ and $\nabla$ no bacteriological examination of the membrane was made. In the other cases it was made, and Loeffler's bacillus was found in each case.

REMARKS.-Owing to the introduction into one of the general wards of the Children's Infirmary of a case of diphtheria in which tracheotomy was urgently required, a number of children and two nurses became infected with the disease. The case (Case I) by which the infection was introduced into the hospital was as severe a case of diphtheria as I have ever seen, affecting the tonsils, soft palate, larynx, and trachea. In ordinary circumstances one would not have expected such a case to have survived tracheotomy more than four or five days. This child, after three injections of antitoxin, lived a fortnight, and appeared to be convalescent, but died suddenly of cardiac failure. After the second injection the membrane seemed to become loosened, and was coughed up-as much as would fill a tablespoon in one day. Case II was also one of severe diphtherial infection, the membrane affecting both tonsils and parts of the soft palate and pharynx. In this case also the injection appeared to produce loosening of the membrane, so that it could be more easily picked off. In the other cases the disease was more limited, and the beneficial action of the injection of antitoxin less observable. In some of the cases which occurred in the hospital no antitoxin was used, owing to the supply (for which we were indebted to Dr. Roux, of Paris) having become exhausted. They were all mild cases, and got well as quickly with local treatment alone as the others had done with local treatment and anti- toxin combined. Our local treatment consisted of frequent syringing or spraying the throat with boracic lotion, and the daily removal of membrane with forceps or with a dry spongestick, and the application of solid nitrate of silver to the raw surfaces. Two of the cases treated with antitoxin (Cases I and IV) afterwards showed signs of diphtherial paralysis. Case IV is now in hospital with general diphtherial paralysis of a severe form. Our experience of antitoxin injection is that it acted with marked benefit on severe cases of diphtheria, but that it did not prevent the occurrence of diphtherial paralysis.

Cases under the care of Dr. Marsh.

CASE vi.-A. B., ag€d 10 years and 9 months, was admitted suffering from a very severe attack of chorea. On October 20 th the temperature rose from normal to $101^{\circ}$, and it was found that the fauces, uvula, and tonsils were much con. gested, and that there was a patch of membrane on each tonsil. There was no albuminuria. Antitoxin $m \times x$ was in jected. About two hours afterwards a scarlatiniform rash appeared on the chest, arms, and legs, in isolated patches. The temperature rose to $104^{\circ}$. The chorea became much worse. By October 22nd the temperature was down to normal ; the rash had nearly disappeared ; the membrane had not spread. He was sent to the Fever Hospital on that day, and was there treated further with antitoxin. By October 24th the membrane had disappeared, and did not re-form. The chorea was also much improved. There was no paraJysis.

CASE VIr.-W. S., aged 1 year and 6 months, was admitted on October 2nd. The child had a cleft palate, was very emaciated, markedly rachitic, and suffering from tetany and laryngismus. On October 21 st it had improved very greatly, but the temperature had been variable during the past two days. It was found that much membrane was present on the cleft palate, on the pharynx. and on each tonsil. Antitoxin m $\mathrm{x}$ was injected. Un Uctober 22nd the temperature war normal; the membrane was as abundant as before; there were no laryngeal symptoms. Slight trace of albumen wa. present in the urine. The child was sent to the Fever Hos pital on that day, and there treated further with antitoxin. The membrane had totally disappeared by October 25th, and the general condition was much improved.

CASE VIIr-A. G., aged 7, was admitted on October 17th suffering from enteric fever. The temperature had gone down to normal on October 21st. On October 29th severe erysipelas of the left arm developed, and the general condition was very bad. On November 1st a large patch of membrane was discovered on the left tonsil, and a smaller one on the right tonsil; the fauces and uvula were much congested. On the next day the general condition was very bad; the pulse was very feeble; the membrane as abundant as before About one-half albumen in the urine. The child vomited many times during the day. The temperature remained normal. In the evening some antitoxin was obtained, and $m \times x$ injected. The child spent a very bad night, vomiting very frequently, and died at 6.30 A.M. on November 3rd.

In each of these cases bacteriological examination showed the presence of Loeffler's bacillus. In Case viII the child's condition was so bad before diphtheria supervened, and the antitoxin was used so late, that there was no prospect of any benefit from its use. Local treatment was used in each case it consisted of frequent painting of the throat with glycerine of boracic acid, or spraying with boracic lotion; and occasional picking off of the membrane where it was very abundant. The injection was generally made into the sub. cutaneous tissue of the lumbar region.

Cases onder the care of Mr. Murray.

CASE 1X.-J. T., aged 7, was an in-patient for abdominal tumour. On October 18th it was found that the fauces. uvula, both tonsils, and the back wall of the pharynx wer thickly covered with membrane. As much as possible was picked off, and the tonsils touched with nitrate of silver. The temperature was normal. Antitoxin $m \times x$ was injected. On October 19th the membrane had re-formed, but had not spread; it was again picked off. The urine contained about one-third albumen. Antitoxin $m \times x$ was again injected During the four days following the membrane re-form ed, but 
not so thickly ; it did not spread. At no time were there any laryngeal symptoms. The albumen diminished gradually. The temperature came down to normal on the fourth day, and remained steady subsequently. On October 24th the membrane re-formed, but the patches were smaller and isolated. On October 27th no membrane remained; of albumen the urine contained only a trace. The membrane did not re-form. The general condition was good.

CASE X.-H. B., aged 3, was, on October 21st, found to have a patch of membrane on the leit tonsil; the fauces, uvula, and right tonsil were congested. During the three following days this patch spread a little, and small patches formed on the right tonsil and the back wall of the pharynx. There was no albuminuria at any time. The temperature never rose above $99.5^{\circ}$. On October 28 th there was no membrane, and it did not re-form.

In each of these eases bacteriological examination showed the presence of Loeffler's bacillus.

\section{THE BRADFORD THROAT, EYE, AND EAR INSTITUTION FOR PAYING PATIENTS.}

THe following circular has been sent round to the members of the medical profession in Bradford, and has,been forwarded to us by Dr. Kerr :-

Dear Sir,

We have opened an institution with the above name to co-operate with and aid the medical profession of Bradford and its neighbourhood. A large number of people in this district who suffer from diseases of the throat, nose, ear or eye, especially astigmatic or other refraction cases which may be difficult to deal with satisfactorily in private practice, are quite unable to afford a specialist's fee, and yet ought

by institutions supported by charitable subscriptions.
We feel that in many cases medical men will welcome a means by which their poorer patients requiring special advice may receive it from a trustworthy source for a fee which they can afford, and without becoming habitués of the charities.

The institution is not a charity, and will neither ask for nor receive subscriptions. No one will be seen gratuitously, a uniform fee of three shillings and sixpence being proposed, with proportionate extra charges in the case of necessary operations. Medical men introducing patients communicated to them by the first post. Under no circumstances will a patient of the institution be aiterwards treated privately by any member of the staff.

We are, Dear Sir,

Yours faithfully,

E. TAYLOR M. R C.S. L.S.A

Late Assistant Surgeon of the Bradford Eye and Ear Hospital.

J. JoHNSTON, M.B.

Assistant Surgeon of the Eye and Ear Hospital. GE. H. DODD, B.A.Cantab, M.R.C.S. et Assistant Surgeon of the Eye and Ear Hospital. AMES KERR, M.A., M.D.Cantab

Honorary Assistant Officer of the Bradford Infirmary; Medical Superintendent of the

November, 1894

We have also received a letter from a practitioner in the town who thinks the proposed institution injurious to the interests of the medical men there, and who requests our opinion whether those of the signatories who are now on the staff of the Bradford Eye and Ear Hospital, and who, he says, receive a salary for their services, ought to be retained on that staff. We prefer to give no opinion on the latter point, which obviously must be decided by the governors of the hospital from their own knowledge of the working of the new institution.

With regard to the plan of forming such a consultative institution, we cannot but see the numerous objections to which it is open, and the great danger that it will result in simply offering to well-to-do persons advice and treatment at ridiculously low fees, for which they could easily pay the usual charges, and for which, under other circumstances, they would be quite willing so to pay. But if the institution is really worked fairly, so as "to co-operate with and aid the medical profession,"as its circular states; if no one is admitted except on the introduction of his usual medi. cal attendant; and if the concluding stipulation of the prospectus is rigidly adhered to, we do not see that there is any conclusive objection to the plan, at least, any other objection than may fairly be made against any other sick club : for, as far as we can understand, the proposed "institution" is really a private sick club. As such, of course, it ought not to be advertised in public, nor do we understand that it'has been so, though paragraphs have been sent to us from local newspapers which have rather a suspicious look.

There can be no question that special knowledge of the affections in question is not at the command of every private practitioner, and that it would be a boon to many a patient, as well as an assistance to his medical attendant, to have an independent and duly qualified opinion at hand at a reasonable fee. We should be inclined, therefore, to watch the scheme jealously, but not to condemn it utterly until experience has been had of its operation.

\section{DEATHS UNDER AN FSTHETICS.}

Dr. A. Ernest Sansom (Harley Street, W.) writes: I was somewhat surpriged to read in the BRITISH MEDICAL JoURNAI of December 8th some criticisms by Dr. Robert Kirk, of Partick, Glasgow, of observations made by myself in the JoURNAL of November 10th. I could not remember that I had written on the subject so recently. I find that Dr. Kirk was in error in attributing to me statements which were made by your contributor, Dr. R. W. Carter, of Weymouth. Dr. Carter quoted a sentence of mine, duly isolating it by inverted commas, and then went on to make the observations which Dr. Kirk visits with much reprobation. Although the sentences criticised, however, were not written by me but by Dr. Carter, I do not hesitate to express my concurrence with them, and I am happy to give Dr. Kirk what he asks for-the grounds on which the statement is based that by the ready or open method of administering chloroform, on a towel or handkerchief, an atmosphere containing at least 12 per cent. of ohloroform vapour may be breathed.

In 1868 I made a large number of investigations on the volatility of chloroform, and on the proportion of the vapour in varying volumes of air passed over it. I had previously, in my book on Chloroform (1866) stated that still air at $40^{\circ} \mathrm{F}$. could retain 6 per cent. of chloroform vapour, and at $60^{\circ} \mathrm{F} .12$ per cent. Air inspired from a surface on which chloroform is poured is, however, air in motion, and I made a series of investigations as to the quantity of chloroform vapour which could be carried by varying volumes of air. I brought these before the British Medical Association in 1868 at the Oxford meeting. A summary of $\mathrm{my}$ views then expressed may be found in the British MEdical JodRnal of August 8th, 1868, p. 149. It is there said: "By a very large number of calculations the author proved that by the common means adopted atmospheres of from three to ten times the necessary strength were employed." My communications in extenso, with all the papers on anæsthetics read at the meeting, were published in the British Journal of Dental Science for September, 1868, and afterwards reprinted. As the exact data may not at the present be very accessible, and as the subject has been so recently discussed, perhaps I may be permitted here to reproduce a portion of the tables, showing the doses of chloroform vapour which air, at temperatures varying from $60^{\circ} \mathrm{F}$. to $64^{\circ} \mathrm{F}$., will convey.

Resulting Atmospheres in Cases of Varying Volumes of Air passed over Chloroform.

\begin{tabular}{|c|c|c|c|c|}
\hline \multicolumn{2}{|c|}{$\begin{array}{l}\text { Quantity of Chloroform } \\
\text { employed. }\end{array}$} & $\begin{array}{l}\text { Quantity of } \\
\text { Air passed } \\
\text { over. }\end{array}$ & $\begin{array}{c}\text { Loss of } \\
\text { Chloroform, } \\
\text { that is, quan- } \\
\text { tity taken up } \\
\text { by the Air. }\end{array}$ & $\begin{array}{l}\text { Percentage of } \\
\text { Chloroform } \\
\text { Vapour in } \\
\text { Resultant } \\
\text { Atmosphere. }\end{array}$ \\
\hline $\begin{array}{c}\text { Fluid Drachms. } \\
\mathbf{2} \\
\mathbf{3} \\
\mathbf{2} \\
\mathbf{3} \\
\mathbf{2} \\
\text { In these in- } \\
\text { stances chlo- } \\
\text { roform was } \\
\text { poured upon } \\
\text { lint. }\end{array}$ & $\begin{array}{c}\text { Grains. } \\
180 \\
270 \\
180 \\
270 \\
180 \\
76.5 \\
38.25 \\
25.5 \\
12.75 \\
6.375\end{array}$ & \begin{tabular}{|c} 
Cubic inches \\
100 \\
400 \\
375 \\
800 \\
750 \\
100 \\
100 \\
100 \\
100 \\
100
\end{tabular} & $\begin{array}{c}\text { Grains. } \\
73.5 \\
195.0 \\
166.5 \\
226.5 \\
172.5 \\
20.0 \\
13.25 \\
12.25 \\
9.75 \\
5.875\end{array}$ & $\begin{array}{r}35.7 \\
27.1 \\
25.2 \\
17.6 \\
14.9 \\
13.2 \\
9.9 \\
8.5 \\
6.9 \\
4.3\end{array}$ \\
\hline
\end{tabular}

It is seen from this table that air, inspired from a surface of chloroform at ordinary temperatures, can be loaded with chloroform vapour to the extent of 35 per cent.; that as the chloroform continues to evaporate the proportion rapidly 